\title{
La etnomusicología y el noroeste de México*
}

\author{
Miguel Olmos Aguilera
}

El objetivo de este artículo es reflexionar sobre la etnomusicología en México en contrapunto con la investigación generada sobre la región noroeste. En la segunda parte del trabajo se identifican algunas características de la música indígena regional, de acuerdo con información etnográfica recogida en rituales de los grupos indígenas de la región, en particular con ejemplos transcritos de música cahíta y de los yumana de Baja California. Finalmente, concluye con un análisis sobre la música de las sociedades indígenas fronterizas, y sobre las implicaciones de realizar investigación etnomusical en contextos inestables propios de las sociedades urbanas.

The aim of this article is to reflect on Ethnomusicology in Mexico in contrast with the academic research generated in the Northwestern region. The second part of the paper identifies some features of regional indigenous music according to Ethnographic data collected during rituals of indigenous groups of the region, especially with transcribed examples of Cahita and Yumana music of Baja California. Finally, it concludes with a reflection on the music of indigenous borderland societies, and on the implications of carrying out ethno-musical research in the changing urban societies contexts which undergo abrupt changes of their cultural system.

miguel olmos aguilera: El Colegio de la Frontera Norte.

Desacatos, núm. 12, otoño 2003, pp. 45-61.

* Agradezco las sugerencias de Gonzalo Camacho y Carlos Ruiz, así como los comentarios de los dictaminadores que me ayudaron a revisar oportunamente algunos puntos de este artículo. 
$\mathrm{E}$ ste artículo presenta, en primer lugar, una reflexión sobre la etnomusicología en México. En el primer apartado señalo, por una parte, el contexto de aparición y establecimiento de la disciplina en nuestro país y, por la otra, realizo una revisión crítica de los estudios generados en la región noroeste, en particular aquéllos escritos por los pioneros de la etnomusicología en Estados Unidos, pero que no incidieron mayormente en los estudios etnomusicológicos en México. ${ }^{1}$ En segundo lugar, identifico algunas de las características sobresalientes de la música indígena regional de acuerdo con la información etnográfica registrada sistemáticamente en fiestas y rituales indígenas, a partir de la segunda mitad de la década de 1980. En el análisis y descripción de la música señalo, por un lado, algunos de los géneros más antiguos de la música indígena con fuerte presencia prehispánica, y por otro, géneros reconfigurados e incorporados recientemente al universo sonoro de la población indígena que habita en el noroeste mexicano.

\section{PRELUDIO}

La etnomusicología se definió en sus orígenes como el estudio de la música de las sociedades de tradición oral. Esta definición marcó la diferencia entre la musicología histórica de carácter principalmente diacrónico —que estudia la música a partir del cambio evolutivo en un contexto temporal-, con el estudio de lo sincrónico o fenómenos que no dependen de la evolución del tiempo, presentándose éstos a menudo como aspectos estructurales, muy privilegiados por la etnología y la etnomusicología. Esta última disciplina vino a ampliar los postulados de la musicología comparada, creada en 1885 por Guido Adler. De acuerdo con este autor, la musicología sistemática se debía encargar del estudio de los aspectos técnicos y teóricos musicales, en contraposición con la musicología histórica avocada sobre todo al estudio de las épocas, las naciones o las escuelas de arte. ${ }^{2}$

\footnotetext{
${ }^{1}$ Pese a que dichos trabajos analizan la música de las culturas que habitan en el territorio de Estados Unidos, estos estudios se inscriben en el contexto musical del noroeste mexicano.

2 Mugglestone (1981: 14-15). Cf. Alan P. Merriam, "Definiciones de
}

No obstante, a partir de 1959, J. Kunst renombra a la musicología comparada como etnomusicología, integrando el aspecto histórico, social y cultural de la manifestación cultural. El término de etnomusicología es recuperado tanto por la escuela anglosajona como por la tradición académica francesa desde mediados del siglo XX. Sin embargo, la construcción paradigmática con infraestructura académica disciplinaria es desarrollada décadas posteriores tanto en Europa como en Estados Unidos y en América Latina en diversos contextos teóricos y epistemológicos. A partir de entonces, la etnomusicología discute sin cansancio el objeto, la teoría y el método propio, lo cual representa un síntoma de desarrollo necesario para la consolidación y afirmación de la disciplina. En esta redefinición constante sobre el quehacer etnomusicológico, han proliferado varias posturas teóricas y metodológicas generadas en cada tradición académica propia de un contexto social e institucional específico. ${ }^{3}$

\section{EL FOLCLORY LOS ARCHIVOS DE TRADICIONES ORALES}

Hasta hace escasas tres décadas, la aproximación a la música tradicional en México se realizaba generalmente desde el folclor, la literatura o la historia nacionalista. Autores como Rubén M. Campos, Vicente T. Mendoza o Samuel

\footnotetext{
'Musicología comparada' y 'Etnomusicología': una perspectiva histórico-teórica”, en Las culturas musicales, Francisco Cruces (ed.), Trotta, Barcelona, 2001, pp. 59-78; y Helen P. Myers, "Etnomusicología", en Las culturas musicales, ibid., pp. 19-39.

${ }^{3}$ Es común que la musicología, más que la antropología, reclame la maternidad de la disciplina etnomusicológica, y peor aún, la supresión de la misma, considerando que toda música debe ser analizada ante todo desde el punto de vista musicológico. En fechas recientes, tuve la oportunidad de participar en una lista de discusión musicológica, que, independientemente de la seriedad de los textos que ahí circulaban, argumentaba reiteradamente la utilización racista del concepto etnomusicología como reducto colonialista por el hecho de discriminar a la música étnica de las otras músicas. Este tipo de apreciaciones intenta reivindicar el discurso original sobre la musicología desde un contexto lejano a la multiculturalidad y a los fenómenos étnicos. Lo importante de realizar el análisis musical desde las referencias culturales no es solamente la reivindicación de la etnología como disciplina, sino de un extenso bagaje epistemológico-antropológico que rebasa por mucho este espacio.
} 
Martí, entre tantos otros, estudiaban el fenómeno folclórico musical con pocos juicios de interpretación antropológica o social. ${ }^{4}$ El folclorista rescataba este tipo de música del lugar más recóndito del territorio nacional con el fin de que la tradición oral no se pierda con el pasar de los años. En el caso mexicano, Vicente T. Mendoza, como folclorólogo y no como folclorista, resalta como una de las figuras más influyentes del estudio del folclor musical desde la década de 1940 hasta lo que en los últimos treinta años hemos llamado la etnomusicología.

En 1936 Vicente T. Mendoza se convierte en miembro fundador del Instituto de Investigaciones Estéticas de la UNAM. En 1938 funda La Sociedad Folclórica de México. En 1945 instaura la cátedra de iniciación a la investigación folclórica en el Conservatorio Nacional de Música, misma que es impartida tres años después en la Escuela Nacional de Música de la Universidad Nacional. Sin embargo, pese a los avances en su prolífica investigación folclórica, Mendoza no poseía en ese entonces ninguna formación rigurosa en el campo antropológico; las únicas referencias al respecto fueron algunos seminarios y lecturas aisladas. ${ }^{5}$ En 1946 viaja a Estados Unidos, particularmente a Chapel Hill, Carolina del Norte, donde toma algunos cursos con Ralph Steele Boggs, folclorólogo a quien Mendoza guardaba especial admiración. ${ }^{6}$ Boggs fue difusor del método histórico-geográfico que, por su influencia, también manejara Mendoza. Dicho método consistía, en términos generales, en clasificar y ordenar las manifestaciones folclóricas de acuerdo con su recurrencia geográfica e histórica. Al igual que el difusionismo antropológico de la época, en el folclor los fenómenos eran sistematizados según su distribución, a partir de un centro común. El origen de este método histórico-geográfico es adjudicado a Julius Krohn de la escuela finlandesa, cuyas enseñanzas se difundieron inicialmente durante la segunda década del siglo XX. El método difusionista en términos

\footnotetext{
${ }^{4}$ Véase de Rubén M. Campos, El folclor y la música mexicana, Secretaría de Educación Pública, Talleres Gráficos de la Nación, 1928, asî como la obra de Vicente T. Mendoza, Panorama de la música tradicional de México, UNAM, 1984, y la obra de Samuel Martí.

${ }^{5}$ Meierovich (1995: 123-129).

${ }^{6}$ Ibid., pp. 126-127.
}

antropológicos es enseñado y propagado por distintos folclorólogos, entre ellos Boggs, quien lo enseñó directamente a Vicente T. Mendoza. ${ }^{7}$

En ese contexto "empírico" de investigación se insertaron en México diversos folclorólogos que tuvieron mucha influencia en la investigación musical. No obstante, la consolidación paulatina de la investigación y docencia etnomusicológica desarrolló una visión distinta del oficio y de las músicas producidas en contextos urbanos y rurales. Cada una de las interpretaciones sobre las músicas de tradición oral derivaron de la experiencia académica y de investigación estimuladas por las necesidades de cada centro de estudio.

El enriquecimiento de los archivos de sonido tuvo un papel primordial en el desarrollo de la etnomusicología y de las instituciones donde después se realizaría la investigación musical. Por otra parte, algunos investigadores independientes que no tuvieron nexo institucional, pero que lograron recopilar piezas y sones de música tradicional, también tuvieron cierta influencia en el ambiente que envolvió a la etnomusicología. ${ }^{8}$ Institutos como el Nacional de Antropología e Historia (INAH) y el Nacional Indigenista (INI) fueron los primeros en recopilar el mayor número de materiales sonoros al interior del territorio nacional.

En el caso del INI, sus grabaciones permanecieron centralizadas en el Distrito Federal durante varias décadas. Sin embargo, a finales de las décadas de 1980 y 1990 se transfiere equipo técnico de registro audiovisual a las comunidades indígenas para que éstas sean las encargadas de realizar sus propios materiales audio-visuales. ${ }^{9}$ En cuanto al Instituto Nacional de Antropología, su histo-

\footnotetext{
${ }^{7}$ Ibid., pp. 142-143.

8 Diversos personajes del ambiente folclórico musical de la década de 1970 aportaron información significativa para el estudio de la música tradicional. Sin embargo, pese a que algunos de ellos estimularon indirectamente la investigación musical, y en algunos casos se sumaron a la investigación académica, el paradigma de la etnomusicología se ha enriquecido en la actualidad por vías que se vinculan directamente con las ciencias sociales, humanísticas y las artes.

${ }^{9}$ Actualmente el antiguo INI posee en el Distrito Federal un área de etnomusicología encargada de la edición y publicación de discos de música indígena. Asimismo tiene un Centro de Investigación, Información y Documentación de los Pueblos Indígenas de México (CIIDPIM), en el cual se ubica la fonoteca Henrietta Yurchenko.
} 
ria es más antigua. Su acervo se nutre durante los años cuarenta y cincuenta, pero no es hasta la década de 1960, con Thomas Stanford, que la fonoteca es reorganizada y enriquecida sistemáticamente con grabaciones de campo. ${ }^{10}$ Por su parte, José Raúl Hellmer trabajó en el Instituto Nacional de Bellas Artes en la sección de música desde su creación en 1947, bajo la administración de Carlos Chávez. Hellmer enriqueció la fonoteca del INBA con grabaciones de música indígena y tradicional de los estados de Morelos, Michoacán, Puebla, Estado de México y Veracruz, entre otros. Asimismo, entre 1962 y 1964, Hellmer produjo un total de 96 programas para Radio Universidad, en los que difundió materiales y donde hablaba sobre tópicos del folclor. ${ }^{11}$

Aun cuando la presencia de estos institutos nacionales ha sido esencial, otros centros han enfocado su interés en la investigación etnomusicológica. El acervo de El Centro de Estudios Lingüísticos y Literarios de El Colegio de México se ha especializado en los últimos diez años en la música de las décimas jarochas del estado de Veracruz y en la música del huapango arribeño de los estados de Nacional de Antropología e Historia (ENAH), heredera de una vieja tradición de grabación, posee también uno de los archivos sonoros más importantes del país. En esta institución se desarrollan varios proyectos sobre la música del centro del país. En cuanto a la Escuela Nacional de Música, ésta posee importante información fonográfica derivada de los proyectos de investigación de maestros y estudiantes de la licenciatura en etnomusicología. ${ }^{13}$

${ }^{10}$ No obstante el trabajo realizado en la década de 1960 , se reconoce que la fundación formal de la fonoteca se realiza en 1974. http:// www. semfonotecas.unam.mx/fono01.html

${ }^{11}$ Margarita García Flores, "Entrevista a José Raúl Hellmer” (1968), Heterofonía, núm. 102-103, p. 47. Cf. artículo de Aurora Oliva y Fernando Hijar, "Homenaje a Raúl Hellmer. 30 aniversario luctuoso", en Crónica. Boletín de Antropología Iberoamericana, agosto de 2001, http:// www.plazamayor.net/antropologia/archtm/11ago/cronical.html

12 En este apartado es posible incluir el trabajo coordinado por Margit Frenk, Cancionero folclórico de México, 5 vols., El Colegio de México, México, 1975-1985, que pese a no ser una obra musicológica, sí destaca como uno de los estudios importantes de la lírica popular mexicana.

${ }^{13} \mathrm{Al}$ inicio de la década de 1980 la enseñanza de la disciplina se realizaba solamente en seminarios aislados en la Escuela Nacional de An-
Con todo, la investigación etnomusicológica se realiza actualmente en instituciones de investigación y docencia como el Centro de Investigaciones y Estudios Superiores en Antropología Social (CIESAS), El Colegio de la Frontera Norte (Colef), El Colegio de Michoacán, la Dirección General de Culturas Populares, la Facultad de Filosofía y Letras de la UNAM y la Facultad de Música de la Universidad de Guadalajara, entre otras. ${ }^{14}$

\section{MUSICOLOGÍA, FOLCLOR O ETNOMUSICOLOGÍA}

La etnomusicología, como disciplina relativamente joven, muestra una genealogía intrincada para el caso latinoamericano, contrariamente a lo que encontramos en Estados Unidos o Europa. Esta situación se debe al heterogéneo estudio antes realizado de la música tradicional y a la reciente creación de organismos de investigación relacionados con la disciplina. Lo anterior no significa que en Latinoamérica no se haya fundamentado una tradición académica, sino que las influencias no son explícitas con respecto a la filiación hacia una escuela de pensamiento en particular. $^{15}$

tropología e Historia y en la Escuela Nacional de Música. En la Universidad de Autónoma de Sonora se impartieron estudios de musicología al final de esta década. Por su parte, el Conservatorio Nacional de Música impartía estudios de musicología y seminarios sobre folclor. A finales de esta década, el Consejo Universitario de la UNAM reconoce los estudios de licenciatura en etnomusicología y a principios de la década de 1990 egresa la primera generación de etnomusicólogos de la Escuela Nacional de Música de la UNAM; desde entonces continúa la formación sistemática de etnomusicólogos. Por otra parte, existe también una maestría en ciencias musicales con orientación en etnomusicología impartida en la Universidad de Guadalajara.

${ }^{14}$ En el norte del país, la investigación vinculada con la etnomusicología se realiza de forma aislada entre las radiodifusoras del INI de la región mayo del estado de Sonora, en la estación de Radio Guachochi Chihuahua (Sierra Tarahumara) y en la ENAH Chihuahua. También existe información de que en la ciudad de Chihuahua trabaja un taller de investigación musical de la Universidad Autónoma de Chihuahua. Entre los objetivos de mi proyecto personal está la creación de una fonoteca de música indígena del noroeste de México en el Colef de Tijuana. Esta tarea se inserta, a su vez, como parte de un proyecto de mayor alcance en torno al arte indígena transfronterizo. 15 Los casos de Argentina y Venezuela con Carlos Vega e Isabel Aretz, Fernando Ortiz en Cuba, o Vicente T. Mendoza y Samuel Martí en México, ejemplifican esta situación. 
Como sabemos, la musicología comparada fue una de las ramas precursoras de la etnomusicología. Esta subdisciplina hace contribuciones importantes al estudio de la música de tradición oral, aplicando tanto técnicas de clasificación organológica como sistemas de notación y de análisis musical. ${ }^{16}$ Las investigaciones musicológicas que se realizaron en Europa en las primeras décadas del siglo XX tenían como objetivo el establecimiento de una clasificación instrumental y la comparación de diversas culturas musicales. ${ }^{17}$ Sin embargo, este conjunto de herramientas respondía a un marco musical occidental que en el siglo XIX fue la punta de lanza de lo que entonces era considerado como fin último de la cultura en términos musicales. El espíritu de la época destacaba sobre todo la presencia de culturas musicales no occidentales refiriendo como parámetro la "complejidad" y elaboración de la música europea, considerada como cúspide de la civilización. ${ }^{18}$ Aun con la proliferación de este tipo de interpretaciones, en Europa se gesta paulatinamente una etnografía conformada de folclor, a la que llamarán etnomusicología a mediados del siglo XX.

La etnomusicología se gesta bajo la influencia del folclor de ascendencia antropológica, por una parte, y de inspiración enraizada en la literatura popular, por otra. La consolidación de los Estados nacionales europeos en el siglo XIX, envueltos entonces en una lógica romántica, era un ambiente propicio para la recopilación de literatura que integró paulatinamente a las músicas populares. De esta manera, los folcloristas estudiaron lo musical sin otro afán que el de demostrar lo pintoresco de la tradición en un contexto nacional. Esta situación no fue exclusiva de un país, sino que fue provocada por el desarrollo de los Estados nacionales en los cuales las clases dominantes ocuparon un papel crucial, exaltando la cultura del pueblo como alma de las naciones. En esta conformación política nacional, el folclor ocupó un lugar

16 Cf. Herzog (1928) y Nettl (1954).

17 André Schaeffner, Origine des instruments de musique [1936], EHESS, París, 1994.

18 De manera indirecta, esta concepción del fenómeno musical y cultural tuvo influencia en muchos de los investigadores de música tradicional en México, entre ellos, musicólogos como Samuel Martí (1953) y folcloristas como Vicente T. Mendoza (1984). muy importante al ponerse al servicio de la construcción nacional independientemente del tipo ideológico instalado en el poder.

En Alemania la etnomusicología se perfilaba con la escuela musicológica fundada por E. Von Hornbostel y Curt Sachs, ambos pioneros de la Escuela de Berlín. ${ }^{19}$ Posteriores a la generación de Sachs y de Hornbostel, J. Kunst, M. Kolinski y Georg Herzog, especialmente estos dos últimos, se articularon directamente con la etnomusicología y la antropología de Estados Unidos, donde escribieron la mayor parte de su obra. ${ }^{20}$ Otros etnomusicólogos estadounidenses formados en esta línea genealógica fueron Frances Densmore, Helen Roberts, C. Seeger, M. Hood y Bruno Nettl, quienes en conjunto tuvieron un papel decisivo en la formación de la disciplina en el vecino país del norte.

Como antes hemos señalado, Kunst define en 1959 la etnomusicología como el estudio de la música y la cultura, abandonando así la designación de musicología comparada. Sin embargo, la noción de etnomusicología desde el siglo XIX, no fue en lo absoluto exclusiva del contexto anglosajón. En Francia, investigadores como André Shaeffner crearon desde 1929 el Departamento de Etnomusicología del Museo del Hombre en Trocadero, elevando la etnomusicología al rango de disciplina. Esta paradigmática iniciativa disciplinar dio como resultado la consolidación académica de etnomusicólogos como Simha Arom, Gilbert Rouget, Bernard Lortat-Jacob, Tran Van Khê, Jean During y Hugo Zemp, entre otros, herederos de una tradición epistemológica musical y antropológica propia de una filiación académica cuyos orígenes se remontan por lo menos a la Ilustración.

Por otro lado, en Europa del Este, estudiosos como Bartók, Kodaly y Brâiloüu relizaron notables aportaciones a

\footnotetext{
${ }^{19}$ Los resabios evolucionistas del folclor repercutieron en una rama de la antropología inglesa. Véase la obra de Lang, discípulo de E. Tylor, quien contribuyó a definir una de las ramas de la antropología folclórica. Cf. Ángel Palerm (1977: 61-75).

${ }^{20}$ Mientras que Herzog llega a Estados Unidos en 1928, Kolinski lo hace en 1945, perseguido durante la Segunda Guerra Mundial. Desarrolla su actividad en diversos campos como la musicoterapia, la edición musical, la investigación y la transcripción de músicas folclóricas. Fue fundador de la Sociedad de Etnomusicología. http://www. musiccentre.ca/apps/index.cfm?fuseaction=composer.FA_dsp_home
} 
la música de tradición oral en contextos menos favorecidos por el paradigma académico. ${ }^{21}$

\section{MÚSICAYTRADUCCIÓN}

Las diversas escuelas de etnomusicología desarrolladas en el continente americano o en Europa tuvieron matices teóricos definidos por el contexto de estudio de la cultura en el que se encontraban inmersas. En México, independientemente de la interpretación conceptual del fenómeno musical, la difusión y publicación de la música tradicional han sido muy socorridas. Pese a que una publicación de música debiera ir acompañada de una investigación que fundamente la percepción del material auditivo, la publicación del registro ha sido en sí mismo una manera rápida y eficaz de dar a conocer los materiales recogidos en el campo. Aun con la persistencia de estas prácticas, la etnomusicología contemporánea va mucho más allá. Esta premisa nos enfrenta a un problema epistemológico fundamental a propósito de la representación estética y la interpretación teórica en etnomusicología.

\section{¿QUÉ SIGNIFICA ESTUDIAR LA MÚSICA INDÍGENA?}

Para estudiar la música indígena no basta con la recolección de material; el etnomusicólogo es antes que nada un traductor de códigos estéticos. Ningún tipo de música se explica por sí misma, sino que es portadora de significaciones culturales sobre las que reposa el sentido estético con el que se produjo.

En toda investigación, la traducción o representación de un fenómeno intangible ha sido un reto al que se enfrentan los etnomusicólogos. La interpretación de los fenómenos musicales son efectivamente representaciones de alguien o de algo, y dar cuenta de esta información no

${ }^{21}$ Arom S. y Álvarez-Péreyre, "Etnomusicología", en Dictionaire de l'ethnologie et l'anthropologie, 1991, p. 249. es inocente, sino que involucra al sujeto junto con todo su cuerpo identitario. El mecanismo funciona como si fuera un conjunto de vasos comunicantes, que vinculados entre sí, conformaran una interpretación principal. La traducción de las representaciones musicales da cuenta de la estructura de la identidad cultural. Cuando hablamos de esta estructura identitaria nos referimos a aspectos invariantes del reconocimiento colectivo al interior de una cultura. En este sentido, la parte musical de la cultura es un sistema que participa activamente en el conjunto de conocimientos que soportan la identidad colectiva, y que al igual que otro sistema cultural, es susceptible de modificarse en forma, pero manteniendo en su estructura cambios más lentos. Dichos contenidos estructurales, de carácter musical en este caso, son los que soportan los rasgos de la identidad sensible de un pueblo, presentándose a menudo como fenómenos de carácter arquetípico.

El análisis del mecanismo de producción musical, así como el delineamiento de los nudos de la urdimbre semántica de las representaciones musicales y culturales, define por lo tanto uno de los objetivos del trabajo etnomusicológico. La representación de la música implica forzosamente una interpretación del investigador, o sea, una doble representación. En el momento de interpretar la información musical etnográfica, el investigador la confronta con la información que tenía almacenada en algún lugar de su propia identidad, pero que el contexto musical revitaliza y enriquece con nuevos sentidos afectivos.

A decir de Gonzalo Camacho: "[el etnomusicólogo] transita por los espacios más sensibles de los distintos grupos humanos... En el encuentro de culturas hay una traducción intersemiótica en la que no se da una equivalencia de elementos traducibles”. Agrega que “...en dicho encuentro se construyen códigos puente que permiten enlazar una zona liminal que favorece una mínima comunicación”.22 Por esta razón el papel del etnomusicólogo consiste en involucrarse como sujeto que contribuye a

22 Palabras de Gonzalo Camacho en una comunicación personal grabada. Véase del mismo autor "Hacia una traducción de las culturas musicales: Una reflexión desde la antropología", en TRAD UIC. Publicación de la Escuela de Traducción de la Universidad Intercontinental, año 9, núm. 16, primavera-verano, 2001, pp. 4-7. 
dirimir las diferencias mediante la interpretación y representación de los códigos musicales. ${ }^{23}$

En la representación de la música participan desde los mecanismos más finos hasta los más elementales, como la grabación. ${ }^{24}$ El trabajo de notación y transcripción es otra forma de traducir el mensaje musical. Sin embargo, estas técnicas no abordan la representación simbólica de la cultura musical en sentido estricto, ni analizan las transformaciones a la que se ve expuesta la música de tradición oral, cuya característica principal es su carácter irrepetible: una pieza no es igual a otra que se interpretó anteriormente, y ésta no será igual a la pieza interpretada en el ritual del año próximo.

Respecto a las culturas con un pasado colonial, como en el caso de México y los países de América Latina, la tradición escrita es muy reciente. Existe un nivel muy alto de analfabetismo musical y, por lo mismo, la importancia de la memoria sonora —u "orejeo" — así como del registro acústico están muy por encima de la escritura musical. Esta ausencia de escritura, en particular para las músicas con fuerte influencia prehispánica, implica que el estudioso de la cultura musical de tradición oral debe estar muy conciente de que muchas de estas músicas no fueron concebidas en el sistema temperado, y que a menudo difícilmente pueden quedar plasmadas en el pentagrama. ${ }^{25}$ Con todo, la representación de la música dependerá también de los objetivos de cada investigación y será necesario no solamente integrar el fenómeno sonoro en su contexto, sino analizar el significado de dicha sonoridad.

\section{LA ETNOMUSICOLOGÍA DEL NOROESTE DE MÉXICO}

Antes de pasar a la información musical del noroeste, me detendré a revisar algunas de las publicaciones de música

${ }^{23}$ Véase Olmos, "El sujeto y la etnomusicología", en Diario de Campo, 2000.

${ }^{24}$ A gran número de folcloristas de la música les bastaba con reproducir una interpretación "fiel" del material musical.

${ }^{25}$ En el territorio mexicano hay grupos indígenas que sí poseen tradición de música escrita, por ejemplo, las bandas de aliento de zapotecos, mixes y mixtecos del estado de Oaxaca. indígena producidas en la región. ${ }^{26}$ La primera investigación con datos sobre la música indígena de los estados de Sonora y Chihuahua es el estudio de Karl Lumholtz, escrito en la última década del siglo XIX y publicado en 1902 con el título de El México desconocido. Lumholtz grabó música en el novedoso cilindro de cera que revolucionó la etnomusicología en todo el mundo. En la obra transcribe piezas para la danza de yúmari y rutuburi. ${ }^{27}$ Su estudio destaca por el cúmulo de referencias culturales registradas por el autor, lo cual le permite explicar la música desde su fundamento mítico.

Por otro lado, George Herzog, al viajar a Estados Unidos, se convierte paulatinamente en una fuente obligada para la música del noroeste de México. Al llegar Herzog a ese país fue recibido por Franz Boas quien le transmitió determinantemente su formación teórica. En 1928 Herzog realiza investigaciones entre los yumanos y publica The Yuman Musical Style. Su libro es una perfecta amalgama de teorías difusionistas alemanas y enseñanzas culturalistas de Boas, tan de moda en ese entonces. Poco después, Herzog escribe otro trabajo sobre la música de los indios pueblo y pimas, "A Comparison of Pueblo and Pima Musical Styles" ${ }^{28}$ Con el primer trabajo, este autor abre brecha en el estudio de los grupos yumanos, enriquecido después por varios etnomusicólogos. El mismo Erich Von Hornbostel, influido por las teorías del difusionismo alemán y los círculos de cultura (kulturkreis),

\footnotetext{
${ }^{26}$ Por razones que no explicaré en este espacio, México ha tenido un desarrollo académico centralizado en la capital del país, y la investigación etnomusicológica no es la excepción. Pese a esta situación, un tanto adversa para los estudios musicológicos y etnomusicológicos del norte del país, la región ha sido foco de trabajos pilares en la historia de la etnomusicología mexicana y de Estados Unidos. Dichas investigaciones han dejado un conjunto de grabaciones, audio-transcripciones y etnografías musicales de varios grupos étnicos del estado de Chihuahua, Sinaloa, Sonora, Baja California y del sur de Estados Unidos. Los investigadores estadounidenses a menudo dedicaron sus trabajos al sur de su país, omitiendo la presencia de estas culturas en territorio mexicano.

${ }^{27}$ Pocos años antes que Lumholtz, en el sur de Estados Unidos, W. Fewkes realizó, en 1889, las primeras grabaciones de cantos zuñis en Nuevo México. Cf. Jean Gerley, Introduction à la Connaissance du Folklore musical, Editions Rencontre, 1967, p. 29.

${ }^{28}$ El autor se inclinó hacia el análisis estilístico propio de la tradición musicológica alemana. Cf. G. Herzog, The Yuman Musical Style (1928) y "A Comparison of Pueblo and Pima Musical Styles" (1936).
} 
escribe un artículo, publicado en 1936, sobre las canciones de los fueguinos, en el que trata de encontrar similitudes y contactos entre el estilo musical yumano y el de los indígenas de la Tierra del Fuego. ${ }^{29}$

A finales de la década de 1920 y principios de 1930, la etnomusicóloga Frances Densmore estudia la música de los yumas de Arizona y publica en 1932 Yuma and Yaqui Music. Densmore recopila piezas cucapás y yaquis analizando minuciosamente las características musicales. ${ }^{30} \mathrm{La}$ autora redacta su investigación cuatro años después de la publicación de Herzog (1928) y cuatro antes de la publicación del artículo de Hornbostel en American Anthropologist sobre la música de los fueguinos. ${ }^{31}$ Esta pionera de la etnomusicología yumana y yaqui, así como Helen H. Roberts, Alan Merriam y Bruno Nettl, se convertirán en los etnomusicólogos más prolíficos de la disciplina en Estados Unidos.

$\mathrm{Al}$ igual que Densmore, otros etnomusicólogos de su generación, como Bruno Nettl (1954), estudiaron la música de diversos grupos del sur de Estados Unidos. En su trabajo, Nettl refleja fielmente la vertiente teórica musirealizó aportes significativos al análisis teórico de la etnomusicología, refiriéndose en más de una ocasión a la música de los indígenas del sur de Estados Unidos. Su obra proseguirá durante todo el siglo XX con otras líneas de investigación. ${ }^{32}$ Por su parte, Henrietta Yurchenko graba entre los años 1942 y 1946 piezas de música yaqui y seri. ${ }^{33}$ Entre sus cintas se encuentran registros de sones para la danza del coyote y del venado. ${ }^{34}$

Con todo, los aportes de la etnomusicología consagrados al norte de México han sido escasos y aislados. Salvo

${ }^{29}$ Von Hornbostel (1936: 367).

${ }^{30}$ Estas piezas grabadas por Densmore (1932) son en realidad mitos sobre la creación cantados. En la actualidad, dichos mitos están totalmente vigentes en el sistema de creencias de los grupos yumanos. 31 Von Hornbostel, op. cit.

32 Jean Jacques Natiez y Charles Boiles, "Petite histoire critique de la ethnomusicologie", en Musique en Jeu. Ethnomusicologie, núm. 28, octubre, Seuil, París, 1977.

33 Thomas Stanford, Catálogo de grabaciones del Laboratorio de Sonido del Museo Nacional de Antropología, INAH, México, 1968, p. 238.

${ }^{34}$ Henrietta Yurchenko, "Baile de coyote", The Library of Congres, Archives of American Folksong, disco acetato de 33 rpm, grabaciones hechas en Vícam, Sonora, en 1946.

algunas excepciones, el trabajo de los musicólogos mexicanos es prácticamente inexistente. Algunas aportaciones de Samuel Martí y Francisco Domínguez datan de los años treinta y se inscriben en la línea folclórica descriptiva con matices evolucionistas. Estos musicólogos hacen etnografías musicales de la región cahíta de yaquis y mayos. Martí, por su parte, escribe un ensayo sobre la música yaqui, mientras que Domínguez hace un registro exhaustivo de la música mayo y yaqui transcribiendo decenas de piezas para la danza del venado pascola y matachines. ${ }^{35}$ En un artículo titulado "Música primitiva en Sonora”, publicado en 1953, Martí apunta algunas características de la música yaqui, haciendo uso constantemente de una retórica que entretiene más de lo que explica. Desde entonces, y hasta la década de 1980, ningún estudio etnomusicológico mexicano será producido sobre el noroeste. No obstante la ausencia de trabajos mexicanos, en 1970, Edward Mosser, especialista en la lengua seri, publica junto con Thomas Bowen (quien se dedica a la arqueología), un excelente artículo sobre los instrumentos musicales seris en un número de la revista The Kiva. El artículo es una exhaustiva recopilación de instrumentos sonoros seris, en la que destaca el uso del raspador y de la concha de tortuga, ambos caídos actualmente en desuso.

En la década de 1970 Arturo Warman realizó grabaciones de música yaqui y mayo en el pueblo de Magdalena, Sonora. ${ }^{36}$ Asimismo, Stanford, que trabajó inicialmente en la fonoteca del INAH, efectuó trabajo de campo entre los cahítas haciendo algunos registros de su cultura musical, recientemente reeditados en disco compacto. ${ }^{37}$

En 1987 aparece en español La música en la vida de los yaquis de Leticia T. Varela. Esta investigación, publicada por el gobierno del estado de Sonora, marca una nueva

\footnotetext{
${ }^{35}$ Francisco Domínguez musicalizó la película Lola Casanova, de Matilde Landeta, interpretada por Mercedes Barba Feito en 1949. La cinta está basada en un mito apropiado tanto por mestizos como por seris. Este mito señala que Lola Casanova era una joven mestiza que fue secuestrada a mediados del siglo XIX por un jefe seri quien la convierte a su cultura y con la cual procrea un nuevo linaje.

36 Arturo Warman (1982). Las grabaciones se realizaron cuando Warman trabajó para el INAH.

37 Testimonio musical de México, disco compacto, INAH, 1997, (P) México, 1964
} 
etapa de los estudios etnomusicológicos sobre la etnia yaqui. ${ }^{38}$ El estudio analiza minuciosamente géneros de música pagana y religiosa, como la misma autora los nombra. La investigación contiene un análisis de transcripciones, así como apartados dedicados al simbolismo y a la organología de las principales danzas. En la actualidad, este estudio es uno de los más completos sobre la música indígena del noroeste de México.

Recientemente, Ochoa Zazueta (1997) transcribe 32 ejemplos musicales de la danza de pascola y la del venado, de los mayos de la Florida, en Ahome, Sinaloa. Pese a que el autor no analiza la música vinculada con la cultura, su trabajo de transcripción es una contribución. Zazueta hizo también transcripciones de música yumana entre 1990 y 1998. ${ }^{39}$ Por otra parte, en el contexto de la música mestiza, en el año 2001 aparece un libro de Helena Simonett, Banda Mexican Musical Life Across Borders. La obra trata sobre la cultura de la música de las bandas de aliento en el contexto fronterizo. Las referencias sobre este tipo de música las restringe particularmente al estado de Sinaloa.

\section{EL NOROESTEY LA MÚSICA}

Para estudiar la música del noroeste es preciso ubicarnos en la región en términos históricos y culturales. El noroeste de México, llamado también la Gran Chichimeca, fue habitado por grupos de tradición nómada y de cazarecolección, con excepciones de grupos agrícolas y sedentarios ubicados en los valles cahítas y en la región del altiplano de Chihuahua, en lo que fuera la antigua ciudad de Paquimé. La región noroeste de México, en términos geográficos, se dibuja actualmente a partir del norte de

\footnotetext{
${ }^{38}$ Esta obra fue presentada originalmente como tesis de doctorado en musicología en la Universidad de Colonia, Alemania, con el título Die Musik im Leben der Yaqui. Ein Beitrag zum Studium der Tradition einer mexikanischen Ethnie (1982).

${ }^{39}$ De acuerdo con sus declaraciones, él mismo participó como cantante entre los cucapás de Baja California. La publicación de sus transcripciones de música yumana se encuentran dispersas en revistas regionales como Papeles, revista de literatura regional, publicada en San Luis Río Colorado durante la década de 1990.
}

Sinaloa, el occidente de Chihuahua, el estado de Sonora y la península de Baja California. Si comparamos esta región de la América Árida con el Altiplano Mesoamericano, el noroeste de México posee una precipitación pluvial menor a la del centro del país. Este factor determina, hasta cierto punto, el tipo de representaciones artísticas y musicales presentes igualmente en su cultura general. La música y las manifestaciones artísticas de estos grupos se vinculan tanto con la organización cultural anterior a la conquista, en la que interviene la tradicional concepción del entorno desértico, como con las prácticas de evangelización introducidas por la Compañía de Jesús durante la época misional. ${ }^{40}$

El noroeste de México actualmente está habitado por una docena de grupos indígenas, en su mayoría de origen lingüístico uto-nahua, entre ellos: mayos, yaquis, tarahumaras, guarijíos, pimas y pápagos. En la región, los grupos con tradiciones lingüísticas no uto-nahuas son los seris y los grupos yumanos de Baja California: cucapá, kiliwa, k'miai, paipai y cochimí, que junto con los uto-nahuas suman más de 200 mil individuos. ${ }^{41}$

\section{LOS GÉNEROS}

En las culturas indígenas de la región noroeste se encuentran actualmente géneros musicales asociados con prácticas dancísticas integradas al ritual. ${ }^{42}$ Dichos géneros a menudo son escenificados en un contexto religioso y se insertan en el ciclo ritual de fiestas patronales y del ciclo de Cuaresma y de Semana Santa. Las piezas

\footnotetext{
${ }^{40}$ Miguel Olmos Aguilera, "La herencia jesuita en el arte de los indígenas del noroeste de México”, Frontera Norte, vol. 14, núm. 27, enero-junio, 2002, pp. 201-239.

${ }^{41}$ Cf. Estadísticas históricas de México, t. I, INEGI-INAH, México, 1990; AA.VV., Pueblos indígenas de México, INI, Secretaría de Desarrollo Social, 1994.

42 Personalmente, he centrado mi investigación en el estudio de la música, la mitología y el análisis de los principios estéticos estructurales que fundamentan la creación musical. Algunos resultados de dicha investigación han sido publicados en Miguel Olmos Aguilera, El sabio de la fiesta. Música y mitología en la región cahíta-tarahumara, INAH, 1998, y Les représentations de l'art indigène dans le Nord-Ouest du Mexique: Esquisse de relations entre l'ethno-esthétique et l'ethnologie, Septentrion, Villeneuve D’Ascq, 2002.
} 
mayos, yaquis, tarahumaras y guarijíos para la danza de pascola, o para la danza de matachines, son ejemplos de géneros que fueron expandidos en el noroeste desde el interior de la región durante la época colonial. El foco de las misiones se encontraba principalmente en la región cahíta, y a partir de este lugar fueron difundidas algunas prácticas. La de matachines es una de las danzas de conquista más difundida en el territorio nacional; en el noroeste es practicada por cahítas y tarahumaras, mientras que la danza de pascola es común encontrarla entre yaquis, mayos, guarijíos, pimas, seris y pápagos. De acuerdo con las crónicas de la conquista y con la difusión de la cultura cahíta, consideramos la posibilidad de que los grupos cahítas hayan tenido cierta dominación en la región, incluso antes de la conquista española.

La danza reviste una importancia crucial en el sistema de creencias indígenas, por lo tanto, una clasificación de los géneros musicales sería dada por la articulación de la música con las danzas de probable origen prehispánico y las de conquista. Dentro de las danzas de origen tenemos al yúmari tarahumara, acompañado sólo por una sonaja. El tutuguri es otro género, similar al yúmari, interpretado por los guarijíos situados entre los estados de Chihuahua y Sonora.

Además, con otro conjunto instrumental compuesto por raspadores, tambor de agua y tres voces, se encuentran los cantos de venado de yaquis y mayos. A este tipo de manifestaciones, más o menos arquetípicas, pertenecen también los cantos con raspadores interpretados por los pápagos para la fiesta del venado Bura, o en cierta medida, los cantos de pascola interpretados por los seris. Para el caso de los yumanos, los cantos antiguos son los del kuri-kuri, mismos que reflejan una visión precristiana, alejada de la tonalidad, la rítmica y del contexto sonoro de origen occidental.

Esta breve enumeración basada en las influencias de origen es totalmente susceptible de agruparse de acuerdo con categorías organológicas o de patrones melódicos y acústicos; si tuviéramos que clasificar la música por el tema del canto, encontraríamos que casi todos los pueblos poseen cantos de creación, cuna, guerra, caza y ritos funerarios, estos últimos particularmente evidentes entre los grupos yumanos.

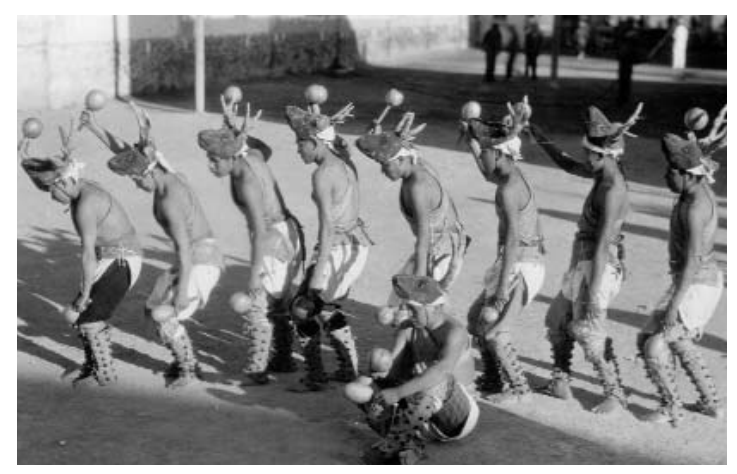

Danza del venado. Foto: Yáñez, colección particular.

\section{SONES DE VENADOY PIEZAS DE CREACIÓN}

Uno de los símbolos, generalizado entre los nahuas del noroeste y del centro de México, ha sido el venado, $m a-$ zatl en náhuatl o maso en lengua cahíta. Este personaje es venerado como deidad presentándose principalmente entre yaquis, mayos, pápagos y, desde luego, entre coras y huicholes de la frontera noroeste de Mesoamérica. A diferencia de los cantos de venado cahítas que narran las experiencias del hermanito-flor, sehuailo-yoréeme en lengua cahíta, los cantos para la danza del venado Bura entre pápagos evocan la creación del mundo, el mar, la Naturaleza. Tanto para yaquis como para mayos, estos cantos suelen ser interpretados en voz de un tercer personaje de la fauna originaria que le canta y venera al hermanito-flor. La diferencia fundamental entre la tradición cahíta y pápago es que entre los cahítas sí aparece en escena un hombre con la cabeza de venado, mientras que entre los pápagos no se presenta. Sin embargo, en el ritual de la caza del venado Bura, entre estos últimos, sí se venera la carne de la caza de venado mediante cantos, utilizando, al igual que los cahítas, tres o cuatro raspadores, pero no utilizan el guaje sino la caja de resonancia confeccionada con un cesto de palma con tejido estrecho. Los pápagos no representan los movimientos y la vida del venado como se escenifica entre yaquis y mayos.

Por su parte, en los cantos de yúmari tarahumara, las letras no refieren directamente la creación. A menudo el texto indica una suerte de peticiones para poder curar alguna enfermedad y agradecimientos por haber obte- 
nido cosechas abundantes. Otra de las manifestaciones musicales, particularmente importante, es la raspa de bacánohua, que no pertenece al género de creación sino al de curación. En este ritual se consumen pequeñas cantidades de la raíz de bacánohua o de peyote, con el fin de pedir a las fuerzas espirituales la curación de algún mal. ${ }^{43}$ Para el personaje del peyote existen múltiples melodías para violín, o cantadas, que sugieren un género musical independiente. Los pápagos poseen también piezas cantadas para el peyote. Se tiene conocimiento de que antiguamente los yaquis sabían de su existencia pero ningún género musical refiere su uso contermporáneo.

Por otro lado, los yumanos, en particular los kiliwas y cucapás de Baja California, utilizando una sonaja o jalmá, al igual que el yúmari tarahumara, interpretan cantos de creación del Universo y sobre los primeros personajes que dieron sentido a su cultura, como el coyote. Además de la existencia de estos géneros, los grupos k'miai, y otros yumanos, poseen un conjunto de piezas que representan el periodo del día y de la noche durante un complejo ciclo musical.

Este fenómeno se percibe recurrentemente en casi todos los grupos del noroeste. El esquema de interpretación temporal está relacionado con el movimiento de la Luna y el Sol durante el ciclo festivo, insertándose en un complejo simbólico asociado con seres míticos y animales de la ecología regional. La hora de la noche o del día determina las cualidades del ser de la Naturaleza que interviene en la pieza. El simbolismo animal y vegetal representado de acuerdo con la hora del día es una práctica muy socorrida entre los grupos del noroeste. El nombre de la pieza está directamente relacionado con la posición del Sol. Dicha noción del tiempo musical y el tiempo astral está bien arraigada en una concepción temporal anterior al pensamiento cristiano.

Una tradición aún vigente entre los cucapás del norte de Sonora y de Baja California son los cantos para los ritos funerarios. Este grupo conserva la tradición de cremar a sus muertos. Para tal efecto, se cantan cuatro canciones de la muerte en cada esquina del lecho mortuorio, tal

${ }^{43}$ Ambas plantas, el bacánohua, Scirpus atrovirens willd, y el peyote, Lophophora williamsii, tienen propiedades psicoactivas.

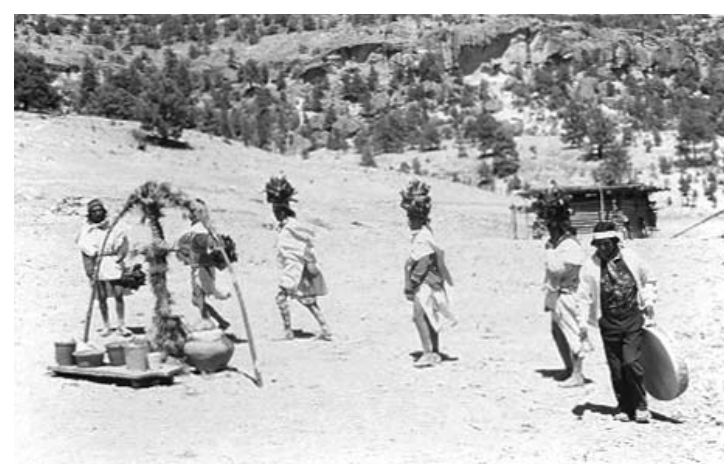

Tesgüinada tarahumara. Semana Santa en Tatawichi, Chihuahua. Foto: Miguel Olmos.

como lo señala la mitología de origen con la muerte de Sipá, deidad creadora en el sistema de creencias cucapá, presente en varios grupos yumanos.

Los grupos indígenas del noroeste poseen una vasta y rica tradición musical. Solamente la música yumana posee al menos cinco variantes que se pueden clasificar grosso modo en igual número de géneros: a) cantos cosmogónicos, b) cantos de funeral, c) cantos de juego de peón y d) cantos de curación.

En algunos cantos el patrón rítmico de la sonaja yumana se expresa como dos octavos .. .5 marcados. Sin embargo, a la mitad de la canción el cantor hacer resonar la sonaja, reafirmando el patrón con un cuarto y luego dos octavos $\theta . \delta$. Esta intención marca el término de un ciclo y funciona como señal para los danzantes. En otros sones yumanos se presenta un patrón rítmico ternario ligeramente acentuado .D.D. No obstante, la acentuación del tiempo fuerte no es parte del estilo musical indígena. Este rasgo se percibe también en la pieza Una señora va llorando por el valle, interpretada por Paulina Vega. En esta pieza no es fácil seguir el pulso de la acentuación de la sonaja, pues a veces da la intención de tresillo (véase p. 62).

En lo concerniente a las melodías de las piezas yumanas, éstas poseen cinco o seis notas y en general la melodía descansa en el cuarto grado en forma de melisma, hasta hacer un salto de tercera mayor ascendente o cuarta justa descendente. Lo importante de la estructura de las piezas es la repetición de las frases, así como los cortes y las señales. 
Canto de Lloro ${ }^{44}$

Una señora va llorando por el cerro

(Interpreta Paulina Vega)
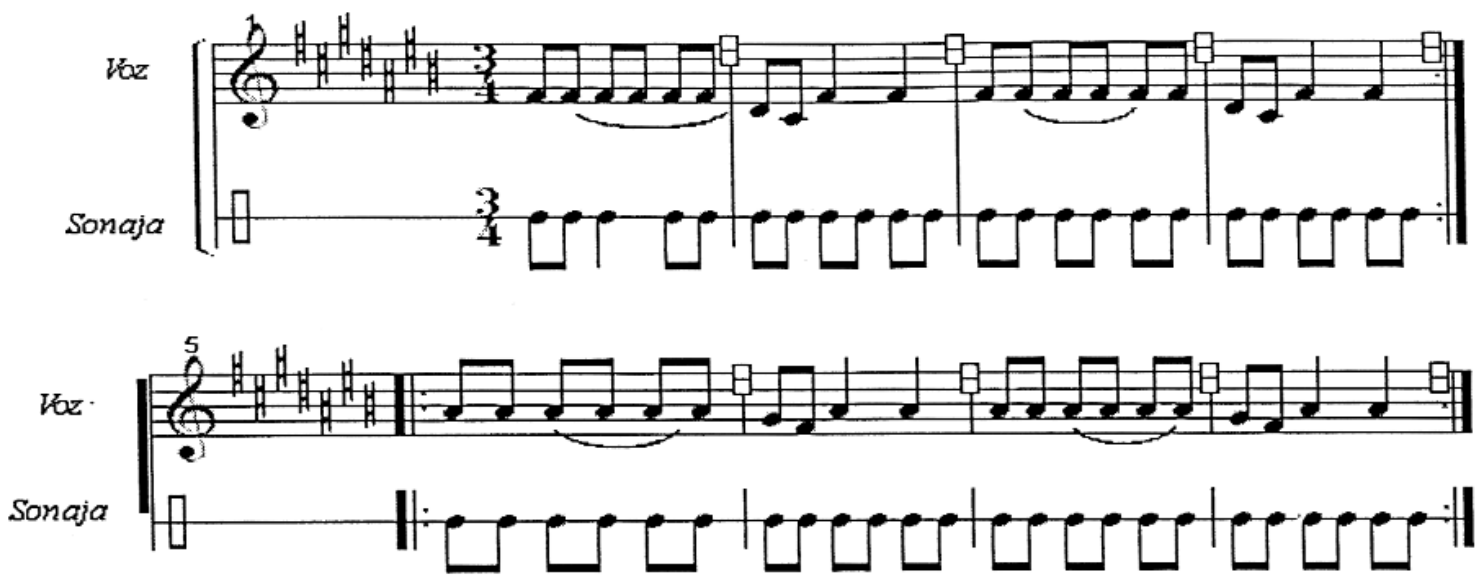

\section{LOS SONES DE CANARIO}

$\mathrm{Al}$ igual que las folías o las zarabandas, las piezas de ca-

narios pertenecen a un género musical para la danza del mismo nombre, que si bien se cultivó en los ambientes populares de Europa o América, al igual que la zarabanda, fue adoptada rápidamente por las clases aristócratas. Las piezas de canarios europeas se ejecutan en tiempo ternario de $3 / 8$ o en sesquiáltera de $6 / 8,3 / 4$ como los canarios de Gaspar Sans. Este género fue traído por jesuítas y ha sido apropiado por muchos grupos indígenas del noroeste con otra lógica musical. El canario se cultiva en algunas zonas indígenas del territorio mexicano y se ejecuta al inicio de una festividad. ${ }^{45} \mathrm{El}$ son del canario en el noroeste es interpretado con arpa y violín como preludio para la fiesta y para la danza de pascola entre guarijíos, mayos y yaquis. Entre mayos y guarijíos este son indica también el final de la fiesta. Para los yaquis existen varios tipos de canario; es posible escuchar el primer canario al inicio de la fiesta, luego se interpreta el

${ }^{44}$ Esta pieza fue grabada por el autor en la comunidad de San José de la Zorra, en el municipio de Ensenada, Baja California, en mayo de 2001.

${ }^{45}$ Lo mismo sucede con los minuetes tarahumaras que son piezas de inicio o suertes de misas introductorias para la danza de matachines. segundo o el hermanito del canario. Una de las características de este son es que hace un movimiento constante del primero al cuarto y quinto grado de una tonalidad, interpretado generalmente en La Mayor. ${ }^{46} \mathrm{Al}$ igual que el canario europeo, el son de canario indígena posee una intención dinámica. Al lado de los sonidos de los capullos de la sarta de mariposas con pequeñas piedrecillas, enredadas en las pantorrillas del danzante, los sones forman una atmósfera especial que despierta los ánimos para iniciar la fiesta.

$\mathrm{Al}$ igual que se implantaron los sones de canario, la conquista y la evangelización dejaron otras tradiciones dancísticas y musicales. Las danzas de tipo morisco, que en muchos casos se convirtieron en los matachines, se extendieron por todos los territorios conquistados, sirviendo como arma de asimilación debido a su profundo simbolismo de conversión al representar las batallas para recuperar territorios ocupados por árabes durante

${ }^{46}$ Este movimiento armónico se trata de un motivo de inicio que repite los movimientos del primer grado de una tonalidad para pasar rápidamente al cuarto grado y descansar en el quinto grado, hasta que entre la melodía propiamente. Un ejemplo ligeramente similar se percibe en los acordes de algunos sones jarochos de Veracruz y en las chacareras chilenas y argentinas. 


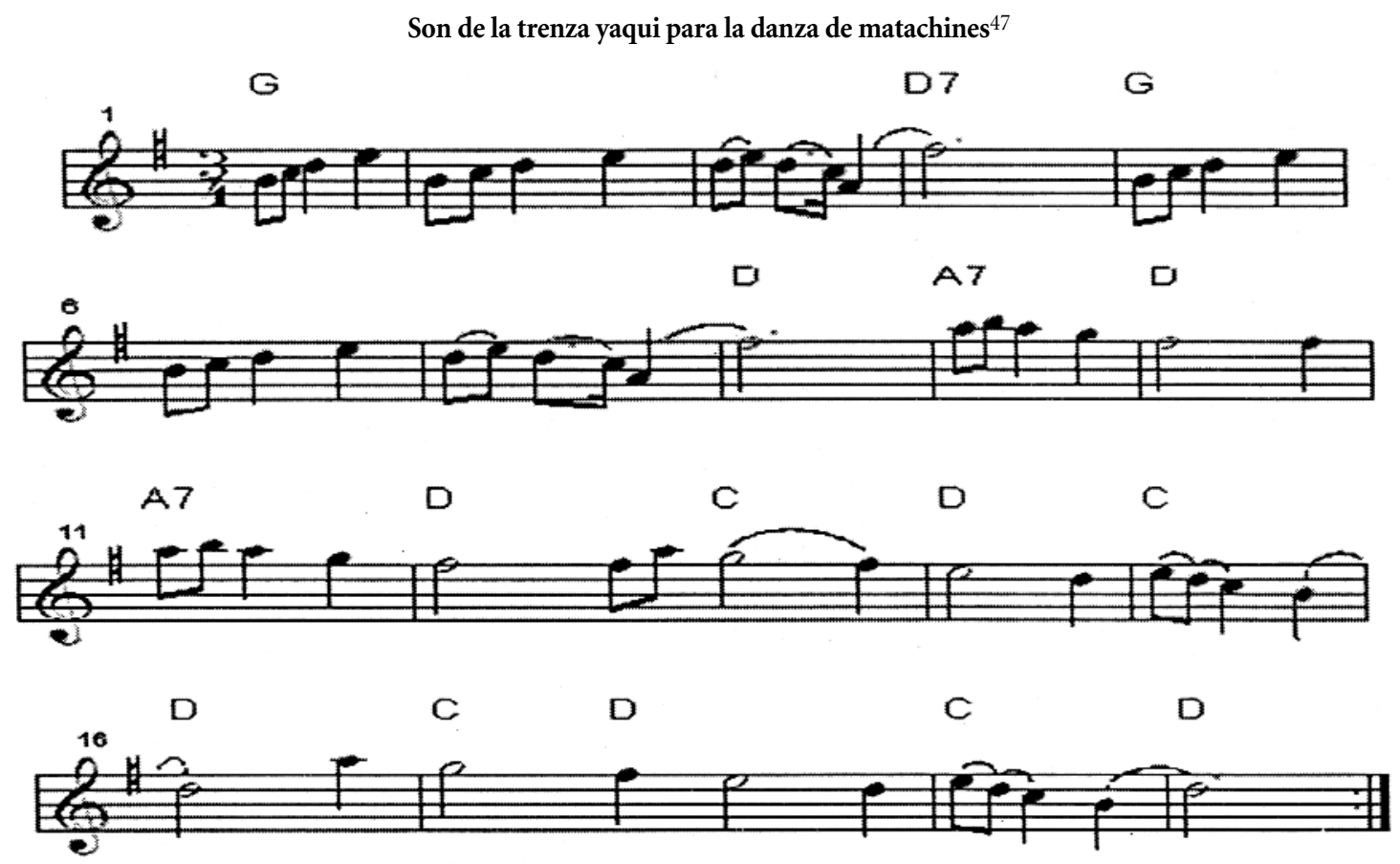

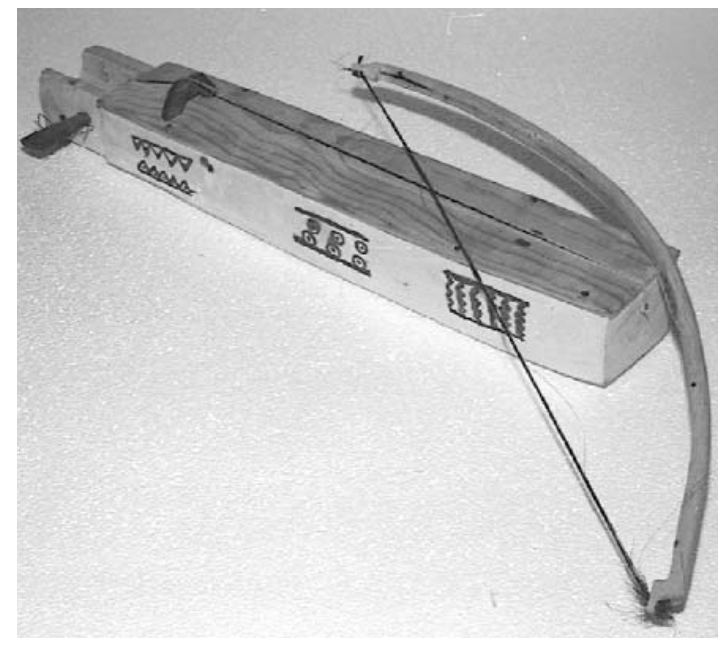

Monocordio seri, col. INAH, Hermosillo. Foto: Miguel Olmos.

${ }^{47}$ Son interpretado por Ismael Castillo Rendón. Grabado por el autor en abril de 1995 en la comunidad yaqui de Pótam. la Edad Media. Actualmente las danzas de matachines expresan todo el simbolismo guerrero original, con su atuendo de corona, representando a menudo la confrontación real o simbólica entre dos bandos. La estructura de las piezas de matachines yaquis son generalmente en tiempo binario marcado por la sonaja de los danzantes y llevado por la guitarra alternando bajo y acordes; sin embargo, existen también melodías que poseen una fuerte intención ternaria. Estas piezas son interpretadas por violines y guitarra entre tarahumaras, yaquis y mayos, aunque es común encontrarla en poblados mestizos de Sonora y Nuevo México.

\section{ORGANOLOGÍA}

Como acabamos de señalar, los instrumentos de cuerda como violín, guitarra y arpa fueron introducidos netamente por jesuítas y militares en el siglo XVI. Es probable que el tambor de doble parche estuviera presente antes de las primeras incursiones militares en la región. Existe 
un arco musical o monocordio de origen incierto, o en todo caso de posible origen prehispánico. Este arco musical es utilizado por tarahumaras, yaquis, mayos y seris. Para los rarámuris o tarahumaras, el instrumento lleva el nombre de chapareque y es construido con un quiote de maguey del que tiran dos o tres cuerdas que son rasgueadas en el momento de su ejecución. El chapareque se sostiene horizontalmente tomado con una mano en el extremo, mientras que del otro se apoya en la boca que sirve como caja de resonancia. Hasta hace veinte años los yaquis utilizaron un monocordio como instrumento lúdico. Éste era interpretado de la manera como lo hacen los tarahumaras, pero construido de carrizo. Dicho instrumento cayó en desuso alejado de todo ambiente ritual.

$\mathrm{El}$ arco musical es un instrumento que destaca en la música ritual de huicholes, tepehuanos y mexicaneros del centro del país. En cuanto a los cordófonos seris, es posible que dada la antigua presencia, tanto del arco musical tipo de caza, como del arco de carrizo, hayan

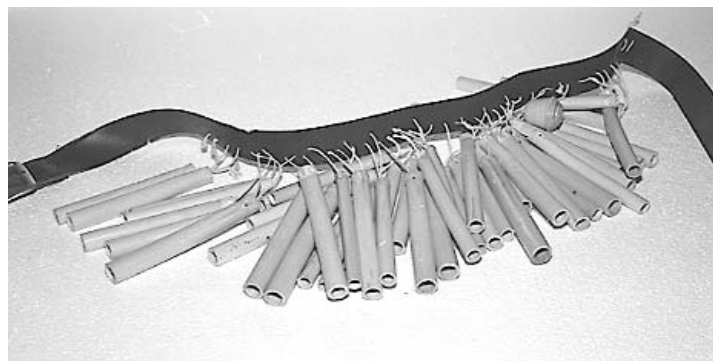

Cinturón de carrizos utilizado por los judíos mayos; col. INAH, Hermosillo. Foto: Miguel Olmos.

influido en la elaboración del violín de una sola cuerda al que llaman enneg. Este instrumento posee una caja de resonancia cuadrada con una sola cuerda frotada por un arco pequeño.

Considerando que diversos grupos indígenas del noroeste tienen una fuerte tradición nómada, una de las características de su instrumentación es la proliferación de pequeños idiófonos. Muchos de estos instrumentos son de fácil transportación y de un estridente color sonoro. A este tipo de instrumentos pertenecen los ténoboim o sartales de capullos de mariposa, los cascabeles, el cinturón de pezuñas de venado o de carrizos, el tambor de agua, que consiste en la percusión de un guaje invertido sobre una palangana de agua (utilizado para la danza del venado), así como el sistro o sena'aso, utilizado para la danza de pascola, con cualidades sonoras totalmente particulares.

En algunas crónicas coloniales se señala la presencia de capas de conchas que funcionaban como idiófonos de sacudimiento. Los idiófonos poseen una función religiosa muy importante en la concepción musical y sonora de los grupos indígenas del norte, además de estar integrados al concierto multisonoro en rituales como los de Semana Santa pues a estos instrumentos se les adjudica la purificación del ambiente. En el caso de la música de los cahítas es posible escuchar diversos instrumentos interpretados simultáneamente: cordófonos junto con idiófonos de sacudimiento, como el sistro, los ténoboim, el tambor de agua, tres raspadores con tres voces de cantores, una flauta y un coro de diez cantoras. Los diversos conjuntos instrumentales asociados a cada danza tocan al mismo tiempo, sin que el ambiente sea percibido como estridente, sino como la cúspide climática del momento festivo.

El raspador utilizado por varios grupos, en particular, amerita un comentario aparte. Este instrumento, muy difundido en el mundo náhuatl, desde la costa del Pacífico hasta el valle de México, se le encuentra en el noroeste entre mayos, yaquis, pápagos, tarahumaras, pimas y seris; y al sur entre coras y huicholes. No obstante, según algunos restos arqueológicos, se le ubica en tiempos anteriores a la conquista entre los antiguos habitantes de Casas Grandes y entre los mexicas del centro del país. Interpretado en las danzas de venado, este instrumento consiste en un madero con estrías que, frotado con una vara seca sobre la mitad de un guaje, invertido y colocado en el suelo como caja de resonancia, produce un sonido similar al del güiro. En la cultura mexica se le utilizaba con el nombre de omichicahuaztli, que significa literalmente raspador de hueso. En la lengua de los cahítas se le llama jirúkiam. El raspador mexica podía estar construido en piedra, madera o de fémur humano. Existen varias representaciones en códices y en restos arqueológicos que comprueban su utilización en el mundo náhuatl. En el norte de México, la prueba arqueológica de un raspador de hueso fue encontrada en Paquimé y actualmente se exhibe en el Museo de Casas Grandes, Chihuahua. 


\section{LO INDÍGENA TRADICIONALY LO INDÍGENA MODERNO}

Debido a los cambios sociales y culturales recientemente introducidos en el orden mundial, sigue vigente la definición clásica del estudio de etnomusicología como el de la música de tradición oral. Sin embargo, una de las premisas del análisis del fenómeno cultural, en particular en las sociedades contemporáneas, ha sido destacar, sobre todo, el proceso de cambio.

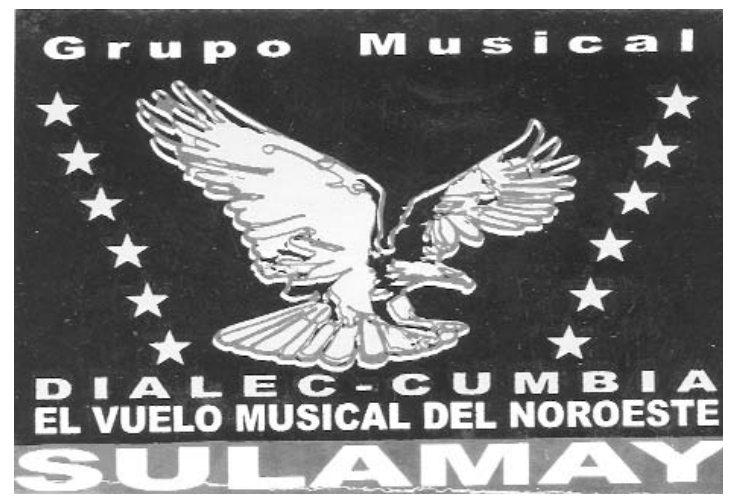

Portada del casete del grupo yaqui Sulamay. Foto y diseño: Sulamay.

Hoy en día se hace necesario estudiar las manifestaciones musicales envueltas en el proceso de cambio, pero dando cuenta de los aspectos fundamentales que definen las transformaciones. No basta con señalar las formas cambiantes en un proceso, sino la lógica de transformaciones que atraviesa el fenómeno, de acuerdo con patrones estructurales que se modifican de manera paulatina. Por ejemplo, en el caso del noroeste de México existen géneros que presentan mínimas variantes desde la época colonial, en los cuales los modelos que los generaron continúan teniendo vigencia. De esta forma vemos que, por un lado, a partir de estos preceptos fundamentales se reinventa la tradición, mientras que en otros se trata de influencias recientes que no tienen que ver con la cultura de origen pero son apropiadas de manera particular.

Algunas expresiones de la música indígena actual del noroeste de México no se restringen a los géneros rituales o a la tradición antigua, aunque ésta represente una parte importante en el desarrollo de la tradición religiosa. La etnomusicología, y la antropología en general, se sitúan en la encrucijada de trabajar con contextos y sociedades que mantienen prácticas culturales que, si bien han sido apropiadas últimamente por el grupo, no responden a una lógica vinculada explícitamente con su "original" sistema de creencias.

Pese a que varios grupos indígenas del noroeste (principalmente los fronterizos) han incorporado otras prácticas y géneros musicales a su música tradicional, ésta se sigue enseñando en muchas ocasiones por vía de la tradición oral. ${ }^{48}$ La sociedad fronteriza ha envuelto a las culturas indígenas en un sistema que atropella y transforma sus prácticas culturales, que en un contexto interno "tradicional" no se trastocarían tan fácilmente. Así, por ejemplo, los seris han incorporado el rock a su música, en un estilo musical muy propio, más allá de cualquier patrón estilístico conocido. De la misma forma como éstos se han apropiado del rock, los yaquis interpretan géneros mestizos como la dialec-cumbia, la balada norteña, el corrido de narcotráfico o la canción ranchera. Asimismo, la versatilidad de algunos músicos los hace intérpretes tanto de música ritual como comercial, demostrando por demás su verdadera bimusicalidad y biculturalidad, brincando de un sistema musical a otro sin dificultad.

Lo mismo que la antropología, la etnomusicología ha tenido que abrir su foco de interpretación analítico hacia músicas que no dependen únicamente de la tradición oral para su producción, transmisión y apreciación dentro y fuera de su contexto cultural. ${ }^{49}$ Actualmente, algunas de las nuevas expresiones de la música indígena se producen con patrones que no están determinados por la tradición oral; sin embargo, una vez que la nueva cultura musical es implantada se desarrolla en la lógica de la memoria tradicional. Aun cuando el análisis de la músi-

\footnotetext{
${ }^{48}$ Los grupos indígenas emigrantes mixtecos y zapotecos que habitan tanto en Tijuana como en San Quintín y en Los Ángeles (Estados Unidos), son la excepción a la enseñanza musical por tradición oral, su música es aprendida e interpretada por partitura. Estos grupos con una fuerte tradición de música de banda han alcanzado una organización musical excepcional en la ciudad de Los Ángeles. ${ }^{49}$ Véase Bruno Nettl, "Últimas tendencias de la etnomusicología”, en Las culturas musicales, op. cit., pp. 115-153.
} 
ca indígena se sirve de diversas modalidades de estudio, cualquiera que ésta sea, presume la traducción de una realidad cultural ajena. Como antes hemos señalado, el etnomusicólogo es un traductor de códigos estéticos musicales. La etnomusicología, como disciplina, no debe pasar por alto manifestaciones artísticas musicales que, si bien no son gestadas al interior de lo que tradicionalmente hemos considerado como un grupo étnico, sí representan un poderoso factor de cohesión en las sociedades mestizas. La música norteña, el corrido de narcotráfico y la música de banda tienen un lugar preponderante en el universo sonoro de indígenas y mestizos de la región. Aparte de estas manifestaciones, existen además otras expresiones musicales de reciente adquisición como la música electrónica que, independientemente de la calidad o de la convicción artística con la que se produzca, es un fenómeno que ha recibido particular impulso entre las manifestaciones culturales musicales de la frontera. Lo cierto es que la sociedad fronteriza de México y Estados Unidos, sobre todo en el contexto mestizo, generan manifestaciones artísticas y musicales que dependen más cos que producen la música al interior de la cultura. No importa sólo estudiar el texto musical sino el contexto, el conjunto de elementos que otorga sentido al universo musical. El estudio de la estética musical nos revelará los principios con los que la música es recreada y asimilada.

\section{Bilbliografía}

Arom, Simha, y Alvarez-Péreyre, 1991, "Ethnomusicologie", en Bonte e Izard (coord.), Dictionnaire de l'ethnologie et l'anthropologie, PUF, París.

Bartók, Béla, 1979, Escritos sobre música popular, Siglo XXI Editores, México.

Blacking, John, 1995, Music, Culture and Experience, University of Chicago Press, Chicago.

Bowen, T, y E. Mosser, 1970, "Material and Functional Aspects of Seri Instrumental Music", en The Kiva. Journal of the Arizona Acheological and Historical Society, vol. 35, núm. 4, pp. 178-200.

Camacho, Gonzalo, 2001, "Hacia una traducción de las culturas musicales: Una reflexión desde la antropología”, en TRD UIC, Publicación de la Escuela de Traducción de la Universidad Intercontinental, año 9, núm. 16, primaveraverano, pp. 4-7.

Curtis, Natalie, 1994, The Indians Book, Gramercy Books, Avenel, New Jersey, pp. 318-320.

Danzas de los Indígenas Mayos del norte de Sinaloa, s/f, disco LD, Gobierno del estado de Sinaloa-Difocur.

Densmore, Frances, 1929, Papago Music, Smithsonian Institution, Bureau of American Ethnology, Bulletin 9o, U.S. Goverment Printing Office, Washington.

Densmore, Frances, 1932, Yuman and Yaqui Music, Bulletin 110, Bureau of American Ethnology.

Dominguez, Francisco, 1933, "Informe sobre la investigación folclórica realizada en las regiones de los yaquis, seris y mayos", en Investigación científica de México, vol. 1, SEPINBA, México, pp. 115-226.

Festival Nacional de Música y Danza Autóctonas, 1982, disco LD, vol. 1, Instituto Nacional de Bellas Artes, CENIDIM, México.

Festival Nacional de Música y Danza Autóctonas, 1982, disco compacto, vol. 1, Instituto Nacional de Bellas Artes, CENIDIM, México.

Grupos étnicos de Baja California Norte, s/f, disco LD, serie I Encuentros de Música Tradicional Indígena, vol. 5, Archivo Etnográfico Audiovisual, Instituto Nacional Indigenista (grabaciones hechas entre 1979 y 1980). 
Herzog, George, 1928, “The Yuman Musical Style”, Journal of American Folklore, vol. 41, pp. 183-231.

_ 1930, Musical Styles in North America (1928), Proceedings, 23rd International Congress of Americanists, Nueva York.

__ 1936, "A Comparison of Pueblo and Pima Musical Styles", Journal of American Folklore, vol. 49, núm. 194, pp. 283-417.

Hornbostel, Erich Maria von, 1936, "Fuegian songs", American Anthropologist, vol. 38, pp. 357-367.

II Festival de las Culturas Indigenas del Desierto, 1992, audiocassette, col. Casa del Viento, Conaculta, Instituto Sonorense de Cultura, Dirección General de Culturas Populares, Unidad regional, Hermosillo.

Loza, Steven, 1990, "Contemporary Ethnomusicology in México", Latin American Music Review, vol. II, núm. 2, diciembre.

Lumholtz, Carl, 1945, El México desconocido, Publicaciones Herrerías, México (Unknown Mexico [1a. ed.], vol. 1., Scribners, Nueva York, 1902).

Marti, Samuel, 1953, "Música primitiva en Sonora”, Órgano del Centro de Investigaciones Antropológicas, núm. 1.

Mendoza, Vicente T., 1984, Panorama de la música tradicional de México, UNAM.

Michel, Concha, 1951, Cantos indígenas de México, Instituto Nacional Indigenista, México.

Natiez, Jean Jacques, y Charles Boiles, 1977, "Petite histoire critique de la ethnomusicologie", en Musique en Jeu. Ethnomusicologie, núm. 28 , octubre, Ed. Seuil, París.

Nettl, Bruno, 1954, North American Indian Musical Styles, Memoirs of the American Folklore Society, vol. 45, Philadelphia.

— 1964, Theory and Method in Ethnomusicology, Schirmer Books, Nueva York.

— 1985, Música folklorica y tradicional de los continentes occidentales, Alianza Editorial, Madrid (A.M., núm. 22).

Ochoa Zazueta, Jesús Ángel, 1997, Los mayos, alma y arraigo, El Correo, México.
Olmos Aguilera, Miguel, 1998, El sabio de la fiesta. Música y mitología en la región cahíta-tarahumara, INAH, México.

— 2000 , "El sujeto y la etnomusicología", Etnomusicología mexicana. Diario de Campo, supl. 11, octubre, Coordinación Nacional de Antropología del INAH, México.

—_ 2002, Les Représentations de l'art indigène dans le Nord-Ouest du Mexique: Esquisse de relations entre l'ethno-esthétique et l'ethnologie, Presses Universitaires du Septentrion,Villeneuve d'Ascq.

_ 2002, "La herencia jesuíta en el arte de los indígenas del noroeste de México", Frontera Norte, vol. 14, núm. 27, enero-junio, pp. 201-239.

Palerm, Ángel, 1977, Historia de la etnología: Tylor y los profesionales británicos, CIESAS, México.

Rouget, Gilbert, 1968, "L'ethnomusicologie", en J. Poirer (ed.), Ethnologie General, Gallimard, París.

Schaeffner, André, 1994, Origine des instruments de musique (1968), EHESS, París.

Simonett, Helena, 2001, Banda Mexican Musical Life Across Borders, Wesleyan University Press, Middletown, Connecticut.

Sistema de Radiodifusoras Culturales Indigenistas. Testimonio musical del trabajo radiofónico Instituto Nacional Indigenista, 1995, disco compacto, vol. 1 y 2, Instituto Nacional Indigenista, México.

Stanford, Thomas, 1968, Catálogo de grabaciones del laboratorio de sonido del Museo Nacional de Antropología, INAH, México.

V Festival de Música y Danza Indígena, 1994, disco compacto, Instituto Nacional Indigenista, México.

Varela, Leticia T., 1987, La música en la vida de los yaquis, Gobierno del estado de Sonora, Hermosillo.

Warman, Arturo, 1982, Música indígena del noroeste, disco de acetato, serie discos INAH-05, Instituto Nacional de Antropología e Historia.

Yurchenko, Henrietta, "Baile de coyote", The Library of Congres, Archives of American Folksong, disco acetato de 33 rpm, grabaciones hechas en Vícam, Sonora, en 1946. 